Case Report

\title{
Delayed Endovascular Coil Extrusion Presenting as a Foreign Body of the Throat: a Case Report
}

\author{
Anup Singh, MD', Kapil Sikka, MD', Nishchint Jain, MD², Leve Joseph Devarajan, MD²
}

Endovascular treatment is a standard mode of treatment for traumatic cavernous internal carotid artery (ICA) pseudoaneurysms with good results and relatively low rates of complications. We describe a case of an unusual, potentially fatal, delayed postoperative event happening in a case of post-traumatic pseudoaneurysm of ICA, which had been previously managed with endovascular coiling.

Key Words : Aneurysm; Internal carotid artery; Endoscopy; Embolization

Endovascular coil herniating from cavernous carotid into paranasal sinus and thence into throat is a seemingly benign potentially life threatening occurrence. In our case, vigilance on the part of the patient and physician resulted in the successful management of potentially fatal outcome of the event.

\section{CASE REPORT}

A 25-year-old fireman with a history of recent fall from a building while on a rescue operation, presented to the department of Neuroimaging and Interventional Neuroradiology with multiple intermittent episodes of

\footnotetext{
'Department of Otorhinolaryngology and Head and Neck Surgery, All India Institute of Medical Sciences, New Delhi, India ${ }^{2}$ Department of Neuroimaging and Interventional Neuroradiology, All India Institute of Medical Sciences, New Delhi, India

Received August 27, 2017; Revised Feburary 2, 2018; Accepted Feburary 3, 2018

Correspondence to: Kapil Sikka, MD

Room no.-4063, 4th floor, teaching block, All India Institute of Medical Sciences, Ansari Nagar, New Delhi-110029, India

Tel.+91.98104.23088 E-mail: kapil_sikka@yahoo.com

This is an Open Access article distributed under the terms of the Creative Commons Attribution Non-Commercial License (http://creativecommons.org/licenses/by-nc/3.0) which permits unrestricted non-commercial use, distribution, and reproduction in any medium, provided the original work is properly cited.
}

epistaxis. The emergency angiogram revealed left cavernous segment traumatic internal carotid artery (ICA) pseudoaneurysm bulging into sphenoid sinus (Fig. 1). This was subsequently treated by endovascular coiling of pseudoaneurysm with occlusion of the parent artery. Post procedure period was uneventful and the patient remained asymptomatic, until around 18 months, when he noticed a constant pricking sensation at the back of the throat, which on examination was found to be metallic wire foreign body at the junction of naso-and oropharynx. A non-contrast CT paranasal sinus confirmed herniation of coil loop into nasopharynx through sphenoid ostium in continuity with initial coil mass (Fig. 2).

He was then referred to the Department of Otorhinolaryngology at our institute, where a nasal endoscopy showed the metallic wire to be hanging down from sphenoid sinus ostium (Figs. 3, 4). In view of the history of endovascular coiling of cavernous segment pseudoaneurysm, the metallic wire was left as such without manipulation. The patient was then taken up in the operating room and under local anesthesia, the wire loop was cut at the level of sphenoid sinus ostium (Fig. 5), taking care not to exert any pulling force on it. No adverse events were observed and the patient was discharged after few hours of inpatient 


\section{Delayed Endovascular Coil Extrusion}

observation without packing.

\section{DISCUSSION}

Traumatic pseudoaneurysm occurs as a result of the partial resolution of periarterial hematoma with the formation of a fibrinous wall, giving rise to a perfused sac, which expands to attain a globular shape under the influence of pulsatile arterial forces. ${ }^{1}$ It lacks a true wall (media and intima) and this differentiates them from saccular aneurysms.

Endovascular treatment involving occlusion of pseudoaneurysm with or without closure of parent artery is established management of such cases. This can be achieved by means of detachable balloons, ${ }^{2}$ coiling, stent placement ${ }^{3}$ or their combination. Endovascular approach results in high cure rates, faster recovery, and low complication rate. The efficacy of the procedure, however, is affected to a great extent by proper case selection.

Our patient, treated for cavernous ICA pseudoaneurysm, with endovascular coiling, presented with herniation of coil wire into nasopharynx after a year, causing irritation of the throat, which was promptly identified and treated endoscopically by cutting it sharply at the level of the sphenoid ostium.

The absence of true wall and resolution of perianeurysmal hematoma/thrombosis with resultant
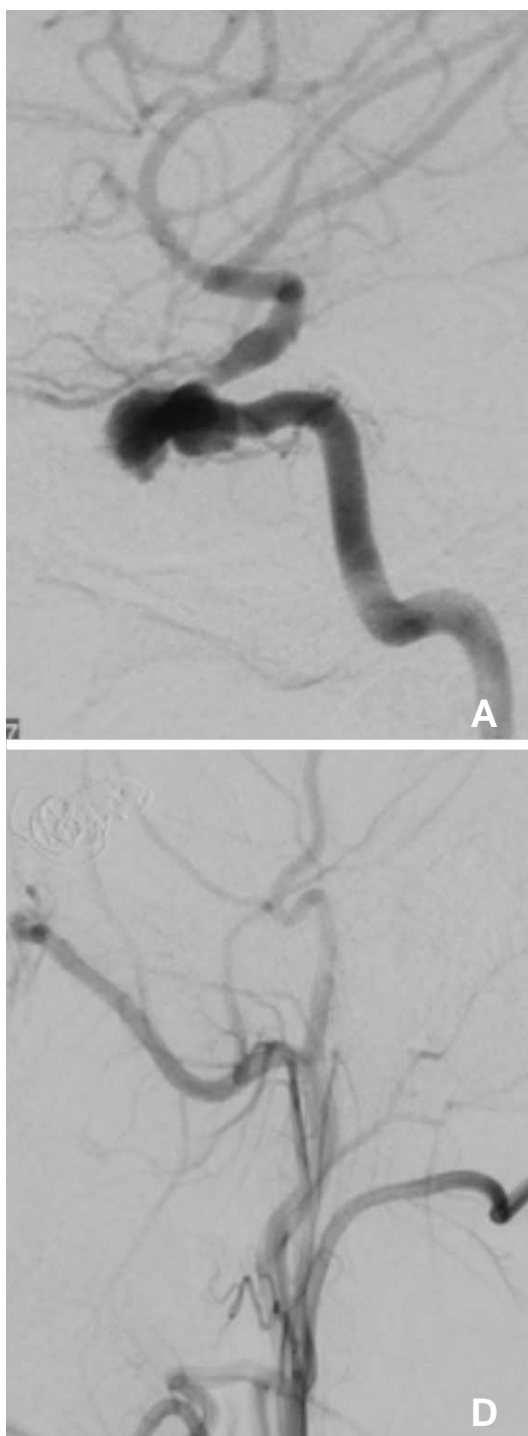
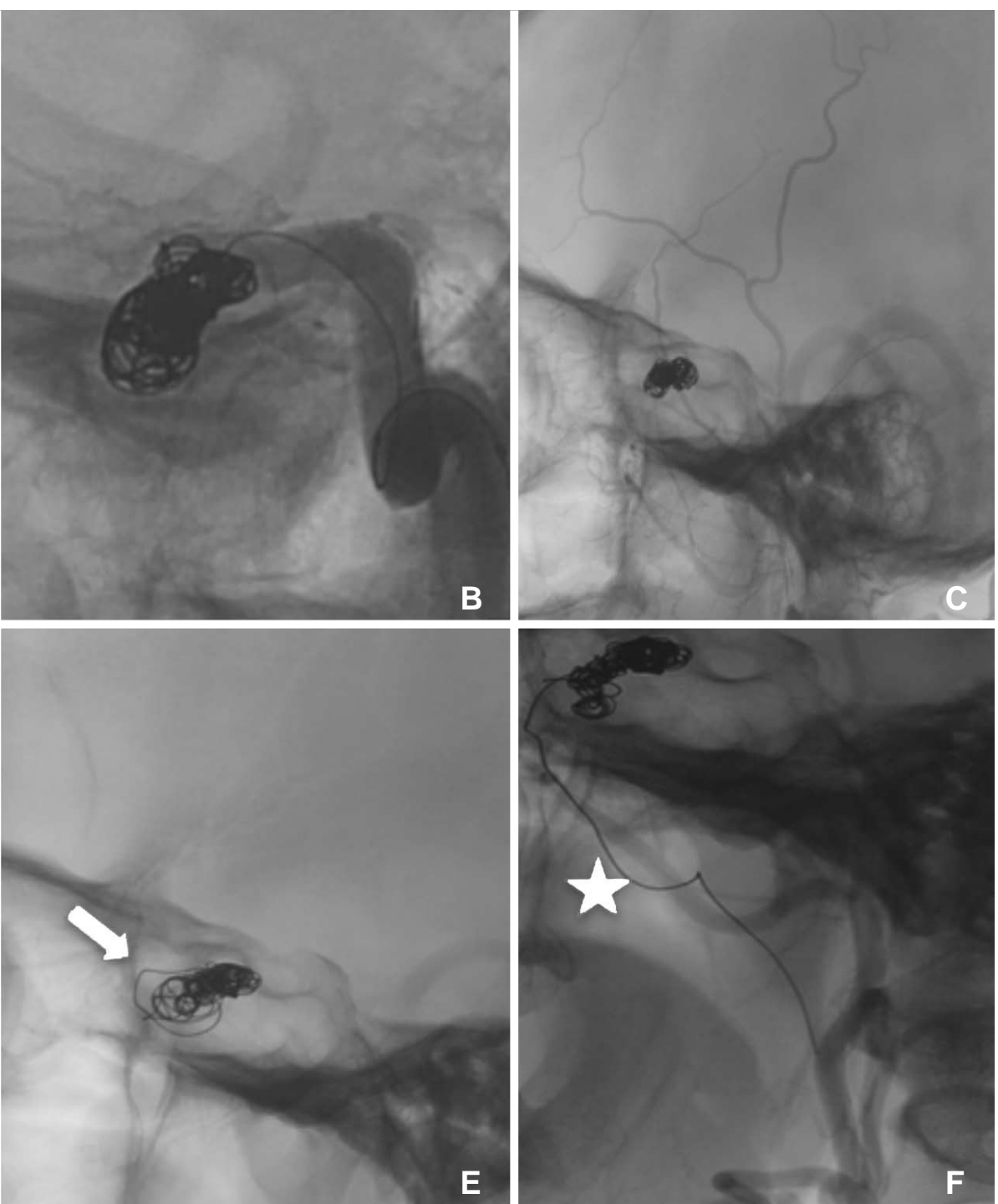

Fig. 1. Left ICA angiogram (A) reveals traumatic left cavernous ICA pseudoaneurysm, which was subsequently treated by coil embolization (B). Final left CCA angiogram (C) shows complete occlusion of both aneurysm and parent artery. Follow up angiogram (D \& E) 1 year later shows stable occlusion of both aneurysm and parent artery, however, loosening of coil mass along its anterior aspect is noted (arrow in E). Two years after embolization, left ICA angiogram $(\mathbf{F})$ shows extrusion of coil loop into oropharynx (star) with stable aneurysm occlusion. 

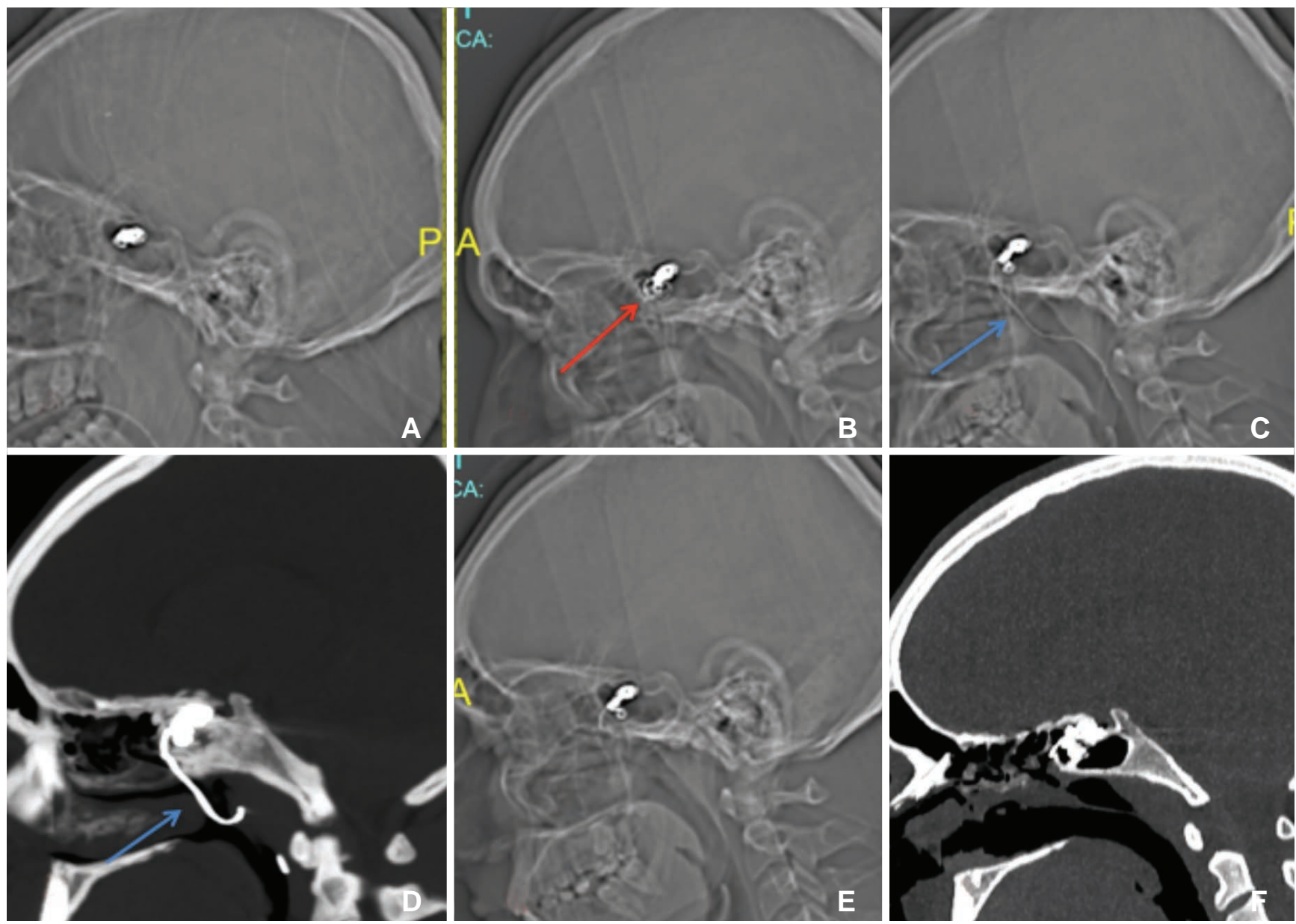

Fig. 2. Lateral skull radiograph $(\mathbf{A})$ immediately after embolization reveals compact coil mass in region of pseudoaneurysm. Follow up radiograph (B) after 1 year shows loosening of coil mass along its anterior aspect (red arrow in B). Lateral radiograph (C) and reformatted sagittal CT (D) on two years after embolization show extrusion of coil loop into oropharynx (blue arrows in $\mathbf{C} \& \mathbf{D}$ ). Final radiograph (E) and reformatted sagittal CT (F), after post endoscopic excision of the herniated coil loop.

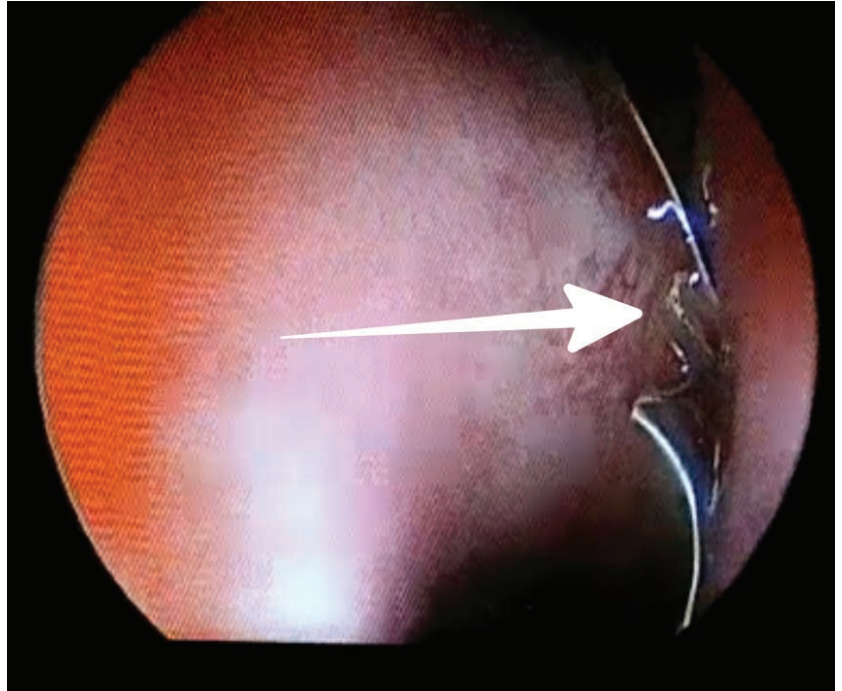

Fig. 3. Closer view inside nasal cavity showing the part of the coil (white arrow) behind middle turbinate.

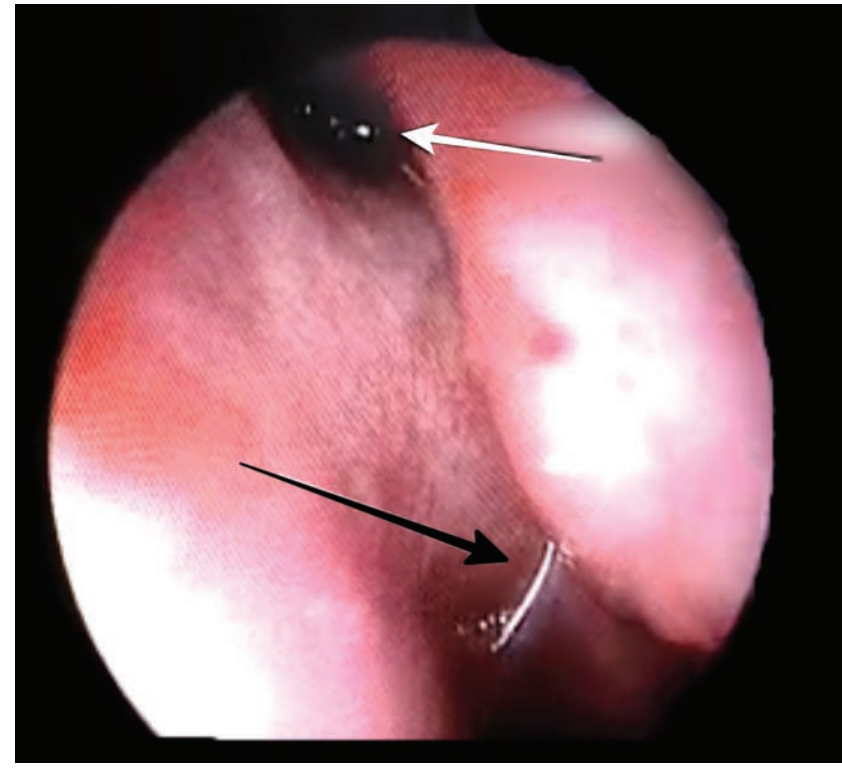

Fig. 4. Nasal endoscopy showing the coil in the nasopharynx (Black arrow pointing to the part in choana and the white arrow showing the part in sphenoethmoid recess). 


\section{Delayed Endovascular Coil Extrusion}

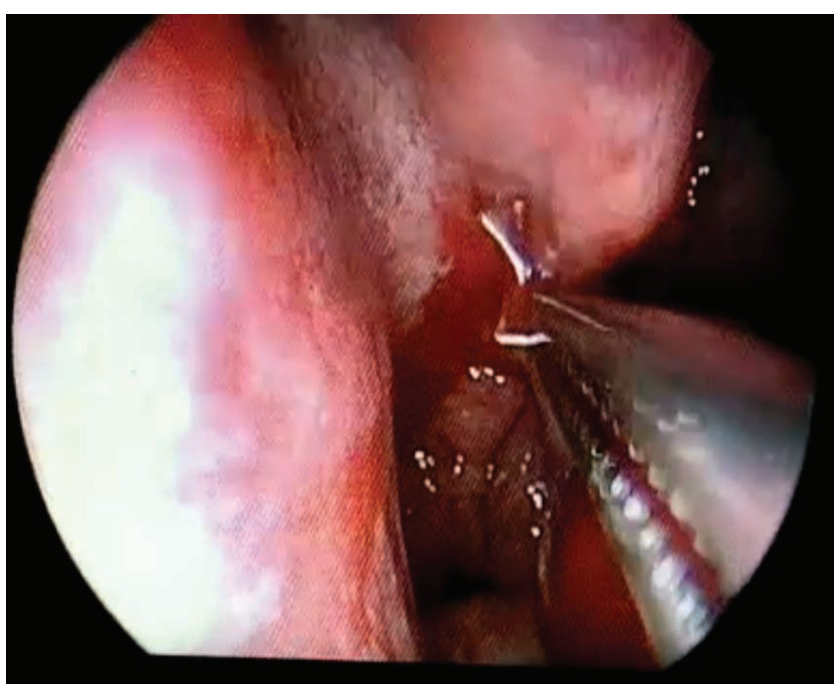

Fig. 5. Coil wire being retrieved endoscopically.

loosening and subsequent migration of coils via preexisting fractures may account for a possible mechanism of coil herniation in our case. Above speculation is validated by careful observation of serial radiographs over past one year which revealed progressive loosening along the anterior aspect of initial coil mass (coil in pseudoaneurysm), whereas posterior part remained compact (coils in parent artery).

The usual complications associated with coiling of such pseudoaneurysms are related to thromboembolic events either from procedural steps or from migration/herniation of coil mass into the lumen of the parent artery. ${ }^{4,5}$ However, migration of coils outside the confines of sphenoid sinus accounts as a very rare complication. A similar case was published by Dedmon et al., ${ }^{6}$ who reported herniation of coil loop from the sphenoid sinus into nasal cavity in an embolized case of cavernous ICA pseudoaneurysm two months after the procedure.

The present case highlights a seemingly innocuous presentation of a delayed yet potentially life threatening complication after a symptom-free interval post intervention. Even though loosening of coils occurred within the pseudoaneurysm, the patient did not present with bleed because of the stable closure of the parent artery. However, vigilance on the part of the patient by not manipulating the wire prevented a potential hemorrhagic event. Care should be exercised when retrieving the prolapsed coil as they have a potential to destabilize the coil mass and culminate in massive hemorrhage.

\section{References}

1. Chen D, Concus AP, Halbach VV, Cheung SW. Epistaxis originating from traumatic pseudoaneurysm of the internal carotid artery: diagnosis and endovascular therapy. Laryngoscope 1998; 108:326-331

2. Higashida RT, Halbach VV, Dowd CF, Barnwell SL, Hieshima GB. Intracranial aneurysms: interventional neurovascular treatment with detachable balloons-results in 215 cases. Radiology 1991;178:663-670

3. Maras D, Lioupis C, Magoufis G, Tsamopoulos N, Moulakakis K, Andrikopoulos V.Covered stent-graft treatment of traumatic internal carotid artery pseudoaneurysms: a review. Cardiovasc Intervent Radiol 2006;29:958-968

4. Levy E, Koebbe CJ, Horowitz MB Jungreis CA, Pride GL, Dutton $\mathrm{K}$, et al. Rupture of intracranial aneurysms during endovascular coiling: management and outcomes. Neurosurgery 2001;49:807811

5. Aken H, Belet U, Enel A. Coil-Induced Perforation of Recently Ruptured Cerebral Aneurysm during Embolization. Causes and Avoidance. Interv Neuroradiol 2003 30;9:83-86

6. Dedmon M, Meier J, Chambers K, Aaron Remenschneider, Brijesh Mehta, Derrick Lin, et al. Delayed Endovascular Coil Extrusion following Internal Carotid Artery Embolization. $J$ Neurol Surg Rep 2014;75:e255-e258 